Para enlazar con este artículo / To link to this article:

http://dx.doi.org/10.6035/MonTI.2018.10.1

Para citar este artículo / To cite this article:

Montalt, Vicent; Karen Zethsen \& Wioleta Karwacka. (2018) "La traducció mèdica al segle XXI - reptes i tendències." In: Montalt, Vicent; Karen Zethsen \& Wioleta Karwacka (eds.) 2018. Retos actuales y tendencias emergentes en traducción médica / Current challenges and emerging trends in medical translation. MonTI 10, pp. $9-25$.

\title{
LA TRADUCCIÓ MÈDICA AL SEGLE XXI - REPTES I TENDËNCIES*
}

Vicent Montalt

Universitat Jaume I montalt@trad.uji.es

Karen Zethsen

Universitat d'Aarhus kkz@cc.au.dk

\section{Wioleta Karwacka}

Universitat de Gdansk wioleta.karwacka@ug.edu.pl

\section{Introducció}

Històricament, la traducció i la medicina han anat de la mà. Una breu mirada a la història revela que la traducció mèdica ha existit des de les formes més remotes d'escriptura cuneïforme sobre tauletes d'argila a l'antiga Mesopotàmia. Els arqueòlegs han trobat un diccionari en sumeri, ugarític i accadi que es remunta al voltant del $1300 \mathrm{aC}$ i que conté informació mèdica en forma precientífica. Molt més tard, al segle V aC, trobem el Corpus Hippocraticum, un compendi de textos que va donar lloc a importants avenços i es va estendre a altres llengües i cultures en segles posteriors, com ara a Galè uns 400 anys més tard, l'obra del qual va ser traduida a l'àrab pels traductors de la Casa de la

\footnotetext{
* Part d'aquesta recerca s'ha realitzat en el marc dels projectes "La mejora de la comunicación clínica interlingüística e intercultural: nuevas metodologías para la formación de los profesionales sanitarios" (FFI2015-67427-P) i "Estudio del Consentimiento Informado y la Consulta Médica en los contextos español y británico: nuevas metodologías para la mejora de la comunicación clínica" (P1-1B2015-73) finançats respectivament pel Ministeri d'Economia i Competitivitat d'Espanya i per la Universitat Jaume I.
} 
Saviesa a Bagdad al segle IX. Entre els segles IX i XII, les traduccions àrabs es van traduir al llatí, acompanyades de comentaris afegits per altres estudiosos àrabs en els anys intermedis (Montalt 2005). Segons Savage-Smith (2001), els erudits medievals i renaixentistes d'Europa es van fonamentar en les tradicions i traduccions islàmiques com a base dels seus estudis mèdics. Seguint Wallis i Wisnovski (2016), les cultures textuals medievals en general, i la medicina en particular, es poden entendre millor com a productes derivats de processos dinàmics de transmissió, traducció i transformació en què els traductors van tenir una funció clau com a agents actius en la reconfiguració i recontextualització dels coneixements i dels textos.

En els segles posteriors, la medicina es va convertir gradualment en una disciplina científica i va experimentar grans avenços, tot generant una quantitat creixent d'informació i, en conseqüència, una necessitat de transferència de coneixement, comunicació internacional i traducció (Montalt 2013). En les últimes dècades, la traducció i la interpretació mèdica s'han convertit en nínxols importants per a traductors i intèrprets professionals. Les autoritats sanitàries nacionals i internacionals - com ara l'OMS o l'EMA -; empreses farmacèutiques que comercialitzen els seus productes en el mercat global; editorials mèdiques que publiquen els llibres per a la formació de futurs professionals en moltes llengües; fabricants de dispositius mèdics de totes les especialitats; hospitals i altres centres sanitaris tant públics com privats; equips de recerca biomèdica que necessiten publicar les seues investigacions en revistes internacionals, normalment en anglès; o ONG centrades en temes de salut - com ara les que actuen en crisis humanitàries -; totes aquestes es troben entre les moltes organitzacions necessitades de traductors i intèrprets. Així, l'àmbit de la traducció mèdica és ric i variat en gèneres, terminologies, registres, estils, formats, modes, així com en cultures de la salut i restriccions i dilemes ètics.

Aquest ric panorama que se li presenta a la traducció mèdica es veu ampliat per tres forces emergents que estan impulsant l'atenció sanitària i la recerca biomèdica cap a nous territoris: l'atenció centrada en el pacient, la medicina personalitzada i la medicina translacional. Totes tres posen de relleu la importància de la transferència d'informació, la recontextualització i la comunicació $\mathrm{i}$, en aquest sentit, ofereixen nínxols potencials per a traductors i intèrprets (Montalt 2017).

La formació especialitzada en traducció mèdica comença a respondre a les creixents necessitats del mercat amb programes específics centrats en les particularitats d'aquesta activitat professional, en l'especialització en el camp mèdic i en els recursos i eines específics. En un món globalitzat i en el cas d'una professió altament internacionalitzada, com és la traducció i la interpretació, 
la formació especialitzada requereix esforços de coordinació i harmonització entre països. Un bon exemple d'aquesta tan necessària cooperació internacional a Europa és l'EMT: màsters europeus en traducció. El seu objectiu principal és millorar la qualitat de la formació del traductor per tal d'augmentar la inserció laboral dels futurs professionals. L'EMT aplega els diferents actors implicats: universitats, empresaris, empleats, institucions governamentals, entre altres, en un esforç per compartir informació i elaborar estratègies en l'àmbit de l'educació superior. El nucli d'aquest projecte és el perfil de competències del traductor, on hom defineix les competències bàsiques - algunes de les quals s'aborden en aquest monogràfic - que els traductors necessiten per treballar amb garanties d'èxit en el mercat actual. Estem convençuts que la recerca pot proporcionar dades i reflexió per facilitar la presa de decisions informades en l'àmbit de l'educació i també en la pràctica professional.

Ara bé, pel que fa a la recerca en traducció mèdica, podríem dir que encara està en una etapa incipient. En el seu estudi bibliogràfic, Franco-Aixelá (2010: 159) assenyala que la recerca sistemàtica generalitzada en traducció i interpretació mèdica es va iniciar a principis del segle XXI i s'ha centrat principalment en els aspectes professionals, la qualitat, la pedagogia, la documentació, les eines i la història. Gran part de la recerca feta anteriorment tenia una orientació predominantment prescriptiva i es limitava a la traducció de textos altament especialitzats. Més recentment, la traducció mèdica ha estat redefinida (Montalt i González 2007; Montalt i Shuttleworth 2012) per incloure-hi no només una gran varietat d'especialitats i conceptes mèdics, sinó també de recursos, textos, situacions comunicatives, organitzacions, contextos i participants. Aquesta perspectiva oberta sobre la traducció mèdica inclou no només textos altament especialitzats sobre recerca biomèdica, sinó també l'educació dels professionals de la salut, l'educació dels pacients, la divulgació i els mitjans de comunicació.

Aquest número especial de MonTI és una invitació a reflexionar sobre la rellevància i l'abast de la traducció mèdica i dels traductors que treballen amb textos mèdics. També és una invitació a explorar com han evolucionat els temes tradicionals de la traducció mèdica - com ara les qüestions terminològiques - i quins nous interessos han sorgit en els últims anys, entre els qual cal destacar la traducció de textos d'experts adreçats a no expert, els perfils professionals dels traductors mèdics, la formació de traductors mèdics o la millora de la comunicació clínica a través de la traducció i la mediació.

\section{La qüestió terminològica}

Lús adequat de la terminologia mèdica és una de les condicions bàsiques per a una comunicació exitosa en comunitats sanitàries monolingües i multilingües. 
La terminologia mèdica és diversa, no només pel que fa a les diferències evidents entre els idiomes, sinó també a causa de diferències entre registres o canals de comunicació. Algunes característiques de la terminologia mèdica es poden observar a través dels idiomes: influències llatines i gregues, afixació (e.g. dermatitis, conjuntivitis, gastritis) eponímia (e.g. Parkinson's disease, Alzheimer's disease) o el fenomen dels doblets: parells de paraules de diferents orígens que s'utilitzen en diferents registres, com ara els anglesos swelling edema, begin - initiate (Salager 1983; Mićić 2013; Uherová, Horňáková 2013; Džuganová 2013). El que sembla ser particularment problemàtic per als traductors i redactors mèdics és l'adaptació de les seues opcions terminològiques a convencions específiques del gènere i del registre. Salager (1983) divideix els termes mèdics en anglès en tres grans grups: anglès bàsic, anglès mèdic fonamental i anglès mèdic especialitzat. En un estudi recent, Fage-Butler i Nisbeth Jensen (2016) inicialment utilitzaren una divisió en termes tècnics i semi-tècnics, que posteriorment es van substituir per una divisió de cinc categories: termes mèdics definits pel diccionari, termes mèdics definits pel co-text, abreviacions mèdiques, noms de medicaments i termes tècnics col-loquials. En cadascuna d'aquestes categories, les diferències entre no experts i experts serveixen com a eixos de divisió i cadascuna d'aquestes divisions reflecteix el fet que les unitats del registre general també s'utilitzen en la comunicació mèdica.

D'una banda, les unitats lèxiques associades al registre general, els doblets, els sinònims i els termes polisèmics semblen estar en conflicte amb els principis de monoreferencialitat (Gotti 2011) o univocitat (Felber 1984) i la necessitat de claredat i precisió en la comunicació interprofessional (Mitzkat, Berger, Reeves, Mahler 2016). D'altra banda, hi ha una forta tendència a evitar la polisèmia i la sinonímia, i a controlar la terminologia mèdica, la qual actualment està àmpliament estandarditzada, en especial en els àmbits dels registres de regulació i dels informes.

L'aparició dels sistemes d'informació mèdica juga un paper important a l'hora d'augmentar la normalització i el control sobre la terminologia mèdica (Cimino 1998; Awaysheh, Wilcke, Elvinger, Rees, Fan, Zimmerman 2017), ja que les classificacions de termes s'integren en els sistemes d'informació sanitària per permetre l'intercanvi electrònic de dades clíniques. Els sistemes terminològics assistencials faciliten el procés de diagnòstic, presa de decisions, redacció d'informes, entre altres. Una de les classificacions més àmpliament utilitzades és la Classificació estadística internacional de malalties i problemes relacionats amb la salut, la versió actual de la CIM-10 aviat serà substituilda per la CIM-11. És una eina de terminologia estandarditzada desenvolupada per l'OMS i utilitzada en el terreny del diagnòstic i l'epidemiologia. La Classificació 
internacional del funcionament, de la discapacitat i de la salut (CIF), també desenvolupada per l'OMS, proporciona un marc per a la descripció de les malalties en els seus quatre apartats: "Funcions corporals", "Estructures corporals", "Activitats i participació" i "Factors ambientals" (OMS 2001). SNOMED CT és un dels principals sistemes de terminologia assistencial; en realitat, és una consolidació de dues terminologies controlades: SNOMED RT i Termes clínics versió 3 (Wang, Barrett, Bentley, Markwell, Price, Spackman, Stearns 2001). Està mantingut per l'Organització internacional de desenvolupament de normes de terminologia de la salut. Els professionals de la infermeria també desenvolupen terminologies formals: la Classificació internacional per a la pràctica de la infermeria (ICNP en les seues sigles en anglès) és un diccionari de termes desenvolupat pel Consell internacional de professionals de la infermeria (ICN en les seues sigles en anglès) per facilitar la descripció i la informació en pràctiques d'infermeria (ICN 2015). La llista anterior no és exhaustiva; de fet, hi ha una gran quantitat de classificacions clíniques (per exemple, ICD, ICF, ICPC, MedDRA, DSM, MEDCIN per al diagnòstic; CPT, CDT, HCPCS per a procediments; almenys diverses classificacions per a infermeria; proves diagnòstiques; dispositius mèdics; entre moltes altre). Una de les raons de les classificacions múltiples és que cap d'elles és universal, tenen diferents finalitats i s'utilitzen en diferents sectors de l'atenció sanitària. No obstant això, han de ser compatibles, ja que les dades es transfereixen entre diferents sistemes. Per tant, la cartografia entre terminologies és, alhora, una necessitat i un repte quan cal alinear terminologies o classificacions per garantir un intercanvi d'informació adequat (Fung 2007, Cardillo 2015).

Els sistemes de terminologia internacional i les classificacions es tradueixen a diverses llengües. La CIM-10 es va desenvolupar en anglès i es va traduir a 42 idiomes per traductors experts, tot i que el terme que l'OMS (2010) utilitza per referir-se a la transferència interlingüística és "representació multilingüe" (no "traducció" per emfasitzar l'equivalència desitjada dels conceptes resultants d'un enfocament semasiològic més que no pas una transferència de paraula per paraula.) La CIM-11 es desenvolupa amb assistència informatitzada i experts humans en el procés de validació per assegurar l'equivalència entre conceptes. L'ICNP s'ha traduitt fins ara a 19 idiomes, inclòs el polonès (ICN 2015). Com que la classificació original està subjecta a actualitzacions, es requereixen noves traduccions per reflectir els canvis en l'original. Les directrius per a la traducció de l'ICNP reflecteixen l'esforç per l'equivalència transcultural de conceptes en comptes de la traducció de paraula per paraula o "equivalència etimològica". Es recomana als traductors "evitar termes ambigus que tenen més d'un significat" (ICN 2008), el que significa que la polisèmia i la sinonímia s'han 
d'evitar. Les directrius de traducció de l'ICN també inclouen recomanacions per evitar frases col-loquials i argot, i una recomanació per abordar les llacunes terminològiques: "si no hi ha cap terme adequat en l'idioma de destinació, traduiu el terme d'origen a un conjunt de paraules utilitzant la definició" (ICN 2008). Aquests enfocaments basats en el coneixement (vegeu Deléger, Merabti, Lecrocq, Joubert, Zweigenbaum, Darmoni 2010) solen involucrar equips de professionals sanitaris i experts en terminologia que realitzen treballs semasiològics i processos de validació abans de proposar termes. Les terminologies o les classificacions també es poden traduir automàticament (o semi-automàticament) amb l'ús de corpus paral-lels i eines d'alineació (Deléger, Merabti, Lecrocq, Joubert, Zweigenbaum, Darmoni 2010). La terminologia coherent, clara i monoreferencial pot millorar l'eficàcia de l'intercanvi d'informació en els àmbits sanitaris i el seu ús adequat en la traducció és un factor de qualitat de vital importància.

\section{Qualitat i traducció mèdica}

La qualitat de la traducció mèdica pot afectar els processos clínics (vegeu Flores et al. 2003), per la qual cosa la funció de la verificació és un altre aspecte freqüentment destacat. Un procés de verificació vàlid comença molt aviat, en la fase de pretraducció, quan es prepara el text origen i s'assegura el compliment de les convencions i requisits de gèneres o funcions de text específics, com ara la llegibilitat i la claredat. Un mètode de revisió de la traducció bastant freqüent però discutible és la retrotraducció (back translation en anglès). L'Associació internacional d'intèrprets mèdics (IMIA en les sigles en anglès) aconsella no aplicar la retrotraducció com a mètode de verificació ja que aquest mètode pot passar per alt "els matisos contextual i d'ús de la llengua meta" (IMIA 2009: 2) així com una traducció literal incòmoda.

Tanmateix, la tècnica de retrotraducció cega s'utilitza amb freqüència en els processos de gestió de la qualitat (vegeu Fernández Piera i Ardura Ortega 2012), especialment en el sector de la investigació mèdica i els assajos clínics, tal i com ho requereixen els comitès d'ètica i les autoritats reguladores en molts països (Grunwald i Goldfarb 2006: 2). Les agències de traducció que s'ajusten a la norma europea ISO 17100: 2015 asseguren la qualitat en l'àmbit dels recursos humans (traductors i revisors competents), la preproducció (com ara la investigació, la viabilitat o l'acord), el procés de traducció (incloent-hi la comprovació, l'edició, la revisió i la correcció) i la postproducció. L'estàndard, però, no proporciona cap mesura per avaluar la qualitat del text traduit i només facilita pautes generals vagues sobre la verificació de la traducció, com ara les relatives a omissions, errors semàntics, gramaticals i d'ortografia, així 
com "assegurar el compliment de les especificacions del projecte de traducció rellevants" (ISO 17100: 2015). Les institucions que gestionen textos traduits desenvolupen els seus propis procediments de verificació de la traducció mèdica. Per exemple, l'Associació internacional d'intèrprets mèdics (IMIA en les seues sigles en anglès) requereix dues verificacions; la Societat internacional per a la investigació en farmacoeconomia i resultats (ISPOR en les seues sigles en anglès) utilitza un mètode de revisió que implica dues traduccions paral-leles, la reconciliació, dues traduccions posteriors, la comparació i la reconciliació, i després una revisió i harmonització del text meta (Andriesen 2006: 15-16).

La traducció paral.lela també es pot aplicar com a mètode de garantia de qualitat autònom: es produeixen dues traduccions paral.leles, després es comparen i s'ajusten si escau (Andriesen 2006: 16). La traducció d'instruments com ara qüestionaris o escales es pot verificar mitjançant un informe de reflexió cognitiva (debriefing), és a dir, recollint els comentaris d'un grup representatiu dels lectors de la traducció sobre com entenen la redacció d'una pregunta o afirmació per verificar si és llegible i comprensible, i alhora reflecteix el concepte original (vegeu Engel, Koester, 2014). De fet, la comprensibitat (en el sentit de lay-friendliness) i la llegibilitat s'han convertit en factors de qualitat crucials, ja que són essencials en la comunicació entre experts i no experts.

\section{Traducció mèdica entre l'expert i el no expert}

En traducció mèdica, sovint hi ha una relació bastant simètrica entre l'autor d'un text i el públic destinatari; és el que anomenem traducció d'expert a l'expert. Tanmateix, durant les últimes dècades, el món occidental ha experimentat una creixent demanda per part de persones "normals i corrents" que volen comprendre les seues declaracions fiscals, les factures de serveis públics, els plans de pensions i, per descomptat, la informació relativa a la seua salut. La dècada dels setanta del segle passat va veure el naixement i expansió del moviment del llenguatge planer (plain language en la seua expressió en anglès) i, en general, d'una societat menys autoritària que dóna suport a la capacitat de comprensió dels no experts, els quals han de ser capaços d'entendre els textos dirigits a ells. Conceptes com ara l'atenció sanitària centrada en el pacient o l'apoderament del pacient es consideren crucials en la comunicació sanitària actual. El concepte d'atenció sanitària centrada en el pacient es va introduir a finals de la dècada de 1960 com un enfocament més innovador i més psicosocial del pensament mèdic. Va exigir que els professionals de la salut tingueren una visió integral dels seus pacients i inclogueren les necessitats i desitjos dels pacients en els seus plans d'atenció mèdica (vegeu Holmström i Röing 
2010, que també revisen les diferents maneres d'entendre tant la centralitat del pacient, la seua capacitació i la seua interrelació). Contràriament a la centralitat del pacient, l'origen de l'apoderament del pacient no es troba dins de l'assistència sanitària, sinó en les teories pedagògiques de Paulo Freire dels anys seixanta i setanta (Askehave et al. 2010). El significat fonamental del concepte és donar poder al pacient, la qual cosa implica fer que el pacient puga prendre decisions importants sobre la seua pròpia salut de forma informada o participar activament en la presa d'aquestes decisions: "L'empoderament és un procés pel qual les persones aconsegueixen un major control sobre decisions i accions que afecten la seua salut." (OMS 1998: 7).

No cal dir que és impossible afirmar que els pacients són el centre de la seua pròpia atenció sanitària o que poden apoderar-se si no comprenen la informació dirigida a ells. En aquest context, el concepte d'alfabetització en salut és fonamental: "Lalfabetització sanitària es pot definir com les habilitats cognitives i socials que determinen la motivació i la capacitat de les persones per accedir, comprendre i utilitzar la informació d'una manera que ajude a promoure i a mantindre una bona salut" (OMS 1998: 10). Cada vegada més, la recerca en comunicació sanitària s'ha centrat en el concepte d'alfabetització en salut, el qual posa l'èmfasi en el fet que, fins i tot entre els no experts, hi ha una gran capacitat d'entendre la informació relacionada amb la salut. Un continu que abasta des de l'absència d'alfabetització en salut, a l'alfabetització funcional en salut, a l'alfabetització interactiva en la salut i a l'alfabetització crítica en salut (Nutbeam 2000). Aquesta àmplia gamma d'alfabetitzacions en salut significa que generalment les traduccions, que funcionen com a una espècie de mitjà de comunicació de masses, és a dir, que potencialment es dirigeixen, per exemple, a tota una població d'un país, ha d'estar orientada al mínim comú denominador.

Un cas concret pel que fa a la comunicació sanitària en massa dirigida al no expert és el prospecte de medicament, que va esdevenir un requisit legal (Directiva 92/27/CEE del Consell) el 1992 (aplicació plena el 1999) per garantir que els pacients entenguen la informació rellevant sobre el medicament en qüestió. Molts textos de comunicació sanitària, com ara el prospecte de medicament, es produeixen per primera vegada en anglès i després es tradueixen a altres idiomes (danès en la següent exemplificació) i aquest fet representa potencialment un perill per a la comprensibilitat. Un perill que un traductor mèdic competent pot eliminar. Contràriament a la situació típica de traducció d'expert a expert esmentada anteriorment, la relació entre l'emissor i el públic receptor és, en el cas que estem comentant, asimètrica. En alguns casos, el text original en anglès encara està dominat per un llenguatge expert ja que l'emissor 
- que és expert - no ha pogut traduir el missatge intralingüísticament. Però fins i tot en els casos en què el text original és molt comprensible o amigable per al lector no expert, sovint veiem que en la traducció el traductor ha tornat a un registre de llenguatge mèdic expert (Askehave \& Zethsen 2000, Nisbeth Jensen \& Zethsen 2012, Nisbeth Jensen 2013).

Alguns dels motius principals que expliquen aquest comportament del traductor semblen ser que més de la meitat dels prospectes de medicaments no estan traduides per traductors formats com a tals, sinó per persones amb formació mèdica, generalment farmacèutics (Askehave \& Zethsen 2000, Nisbeth Jensen 2013). És comprensible que els experts troben dificultats per identificar quines són les expressions que causen problemes de lectura per als profans en la matèria. Tanmateix, fins i tot quan els prospectes de medicaments són traduits per traductors mèdics formats com a tals, hi ha una tendència a tornar al llenguatge mèdic expert (Askehave \& Zethsen 2000, Nisbeth Jensen \& Zethsen 2012, Nisbeth Jensen 2013). Això pot deure's a que aquest és el comportament per defecte del traductor mèdic que s'ha convertit en un semi-expert en la matèria i ha perdut la consciència del que el pacient com a lector no expert pot entendre i del que li resulta més difícil d'entendre. Un altre motiu és que l'anglès utilitza terminologia grecollatina per a moltes expressions mèdiques on el danès (i moltes altres llengües) té un terme expert i un terme no expert, fins al punt que els no experts només saben i usen el terme no expert i desconeixen per complet el terme expert (Zethsen 2004). Fins i tot un traductor (en aquest cas danès) format com a tal pot no ser capaç de traduir intralingüísticament part d'aquesta terminologia de base llatina a llenguatge no expert en la cultura meta, una terminologia que en anglès (i encara més en llengües grecollatines com ara el català o l'espanyol) pot ser perfectament comprensible per al no expert.

En traducció/comunicació medicosanitària, es necessiten més investigacions en dues direccions: la primera és documentar les traduccions que poden resultar exitoses pel que fa al significat denotatiu interlingüístic, però que no arriben al grup meta no expert ja que no assoleixen la part intralingüística de la traducció; i la segona és explorar més profundament el motiu pel qual hom no satisfà les necessitats del grup meta. Potser, l'aspecte intralingüístic de la traducció mèdica entre experts i no experts s'hauria d'incorporar en major grau a la formació de futurs traductors mèdics.

\section{Les contribucions d'aquest monogràfic}

En aquest monogràfic, els autors han abordat un seguit de preguntes d'investigació sobre diversos temes: textos, relacions intertextuals, pacients com 
a lectors, ètica, metàfores, formació especialitzada, multimodalitat, qualitat i retrotraducció. Pel que fa a la metodologia, queda palès que aquests temes exigeixen una gran varietat d'enfocaments, sovint en combinació, per respondre a les preguntes de recerca rellevants en la traducció mèdica. Entre aquestes metodologies trobem tant eines quantitatives - com ara la lingüística de corpus o els qüestionaris - com qualitatives - com ara grups de debat, l'observació directa dels participants, l'anàlisi del gènere textual o l'anàlisi conceptual. Noves metodologies de recerca - com ara "l'anàlisi netnogràfica" (vegeu Bundgaard i Nisbeth en aquest volum) estan obrint-se camí en l'àmbit de la traducció mèdica en resposta a nous formats i entorns de comunicació professional.

Entre els gèneres que han cridat l'atenció dels investigadors, alguns són escrits - el prospecte de medicament, el full d'informació per a pacients i el consentiment informat; d'altres són orals, com ara la consulta mèdica i, en part, el consentiment informat. De fet, el consentiment informat s'ha tractat en ambdós modes en el mateix estudi (Elena Pérez en aquest monogràfic), tot posant l'accent en la complexitat de la comunicació entre metge i pacient, i assenyalant un enfocament més integrat de la multimodalitat. Investigacions recents en aquest sentit (Montalt i García-Izquierdo 2016) subratllen la importància de redefinir alguns gèneres crucials com ara la consulta mèdica i el consentiment informat des d'un punt de vista multimodal en el qual convergeixen els modes oral, escrit i audiovisual, i estableixen una fructífera relació de complementarietat en el repartiment de funcions comunicatives.

L'elecció dels gèneres d'aquest monogràfic mostra un clar interès en la traducció entre l'expert i el no expert, on importants asimetries entre les comunitats discursives determinen la forma en què es produeix la comunicació. Les comunitats discursives dels professionals de la salut, especialment metges i infermers, tenen normes i agendes implícites i explícites, així com un estatus social més alt, que donen lloc - i reflecteixen - un clar desequilibri de poder. En comparació amb els pacients, els professionals sanitaris són molt més homogenis i coneixen millor el sistema de salut des de dins, mentre que els pacients generalment són més heterogenis en les seues necessitats, expectatives, coneixements mèdics previs, així com en procedència cultural i lingüística. A més a més, en el cas del consentiment informat, les asimetries tenen conseqüències jurídiques i ètiques. Els professionals sanitaris són cada vegada més conscients de la importància d'oferir als pacients explicacions comprensibles que puguen fonamentar i raonar adequadament les seues decisions. Lany 2016, la Federació espanyola de col-legis oficials de metges a Espanya va publicar una guia de 
bones pràctiques sobre el consentiment informat en resposta a les creixents queixes dels pacients.

Es poden observar problemes ètics similars en el cas del prospecte de medicament i del full d'informació per a pacients. Els prospectes de medicaments, com Raquel Martínez assenyala en aquest monogràfic, estan altament regulats en el context europeu per fer que el missatge siga comprensible. Tanmateix, com passa amb el consentiment informat, sembla que hi ha un buit entre la llei i les guies de bones pràctiques, d'una banda, i la realitat, d'altra banda. Aquesta tensió entre els sistemes d'experts i el món real també afecta els full d'informació per a pacients.

Trobem un interès creixent en els estudis de traducció orientats al pacient com a lector. El tema de la comprensibilitat (o llegibilitat) és el focus principal de l'article de Raquel Martínez. En aquest cas, el gènere en joc és el prospecte de medicament, un altre gènere emmarcat en la comunicació entre expert i no expert en el qual el pacient porta a terme una funció fonamental. Elena Pérez se centra en la comprensió del consentiment informat en interaccions mediades per l'intèrpret en què l'element crucial és la signatura d'un document de consentiment informat. En ambdós estudis, les autores arriben a la conclusió que la traducció i la interpretació són un guany i no pas una pèrdua. Els pacients estrangers que són assistits per intèrprets en situacions en què el document del consentiment informat no està disponible en el seu propi idioma, semblen comprendre millor el que signen gràcies a la participació de l'intèrpret per facilitar la comprensió. De la mateixa manera, els prospectes traduïts semblen ser més comprensibles que els escrits originalment en espanyol.

Tanmateix, no sempre és fàcil prendre decisions i sovint sorgeixen dilemes ètics - com ara la confidencialitat, la imparcialitat i la no discriminació - en situacions típicament asimètriques, ja que pot existir una discrepància entre les responsabilitats ètiques i els deures professionals. Com hem vist, sovint la traducció i la interpretació mèdica té un component ètic. Els diferents gèneres es regeixen per diferents normes ètiques (Montalt i González 2007), ja siguen implícites o explícites. Aquest elements ètics són el nucli central en l'article de Carmen Pena-Díaz, qui interroga i observa un grup d'intèrprets mèdics. En el seu estudi, l'autora proporciona exemples convincents de com l'intèrpret ha d'explicar els motius d'alguns comportaments tant dels pacients com dels professionals de la salut per evitar malentesos. Això pot estar en contradicció amb el fet que no es recomana facilitar la informació i no hi ha protocols per ometre informació mentre s'interpreta.

Un altre aspecte que tracten els investigadors en traducció mèdica en aquest monogràfic és la pedagogia. Manuel Cristóbal Rodríguez i Emilio Ortega 
centren el seu estudi en el prospecte de medicament en el context francès-espanyol. La seua contribució posa en relleu la utilitat de la lingüística de corpus amb finalitats de traducció i, més concretament, per a la formació de traductors mèdics. Una altra manera d'apropar-se a la formació dels traductors mèdics és a través de la multimodalitat. Partint de la seua pròpia experiència en el context italià, Michela Canepari es planteja l'objectiu proporcionar recursos i solucions motivadores per a l'aula de traducció mèdica. L'ús efectiu de materials audiovisuals per a cursos de traducció mèdica oferts als estudiants que no tenen una formació mèdica contribueix a desenvolupar el lèxic dels alumnes i els seus coneixements previs. Un dels conceptes que explora aquesta autora és el de la traducció intergenèrica.

La qüestió de la traducció intergenèrica en els entorns assistencials es converteix en el nucli de l'article de Muñoz, Ezpeleta i Saiz, però en aquest cas el focus d'atenció és un gènere diferent, el full d'informació per a pacients. La traducció intergenèrica pot implicar la traducció interlingüística, però, per descomptat, sempre la traducció intralingüística. Larticle es basa en un estudi empíric dut a terme pel grup de recerca GENTT (Universitat Jaume I) on es van utilitzar diverses estratègies intralingüístiques per fer més efectius els fulls d'informació per a pacients oncològics. Seguint un plantejament bastant innovador, aquestes estratègies van ser validades pels pacients, i els resultats s'utilitzen com a base per a una proposta de formació orientada a millorar les habilitats dels traductors mèdics per tractar aquest tipus de traducció intralingüística.

Una tercera àrea d'investigació que trobem en aquest volum és la retrotraducció en el camp mèdic. Aquest tema és explorat per Kristine Bundgaard i Matilde Nisbeth Brøgger que van realitzar un estudi netnogràfic sobre les actituds dels traductors envers la retrotraducció. Els resultats que aporten les autores indiquen que aquesta eina de garantia de qualitat en particular necessita més atenció, atès que els traductors no sempre coneixen el procediment o no saben el seu propòsit. Una de les possibles solucions és incloure un requisit per informar els possibles traductors del propòsit i les bones pràctiques amb les directrius rellevants.

Finalment, Sylvie Vandaele s'ocupa de les metàfores mèdiques i les seues traduccions, tancant el monogràfic amb una visió diacrònica. L'autora mostra que els índexs de conceptualització en salut i ciències de la vida formen xarxes lèxiques estables que es poden observar en textos mèdics contemporanis i antics. Són estables però no fixades: les xarxes lèxiques són "conjunts oberts" amb espai per a la creativitat, especialment en el discurs de divulgació. L'autora també dóna espai a un debat rellevant sobre la funció de la traducció automàtica i assistida tant en la professió com en els contextos educatius. 
Aquest debat tecnològic prendrà força en el futur ja que la tecnologia pot generar canvis radicals en els rols socioprofessional i la formació del traductor mèdic. La investigació sobre intel-ligència artificial i traducció automàtica neuronal, juntament amb el desenvolupament de llenguatges controlats i la expansió de l'anglès com a lingua franca, segurament tindran un impacte en la interpretació i la traducció medicosanitària. Alguns dels gèneres altament rutinitzats - com ara els articles de recerca o els resums de les característiques del producte en la indústria farmacèutica -, així com alguns dels processos més mecànics en l'àmbit de la gestió terminològica multilingüe, probablement es beneficiaran de l'automatització. A més, alguns avenços tecnològics milloraran la comunicació multimodal, incloent-hi noves aplicacions mòbils per a pacients que facilitaran una comunicació més personalitzada, més directa i més ràpida.

Al mateix temps, en l'era de la medicina personalitzada i l'atenció centrada en el pacient, no seria massa arriscat anticipar un creixement de la traducció humana amb alts graus d'adaptació (a públics, cultures, formats, etc. molt definits) i de creativitat on l'atenció a l'individu és primordial. En aquest panorama emergent, la qualitat no es limita a la precisió terminològica i l'accessibilitat al coneixement factual, sinó que inclou dimensions interpersonals i actitudinals com ara la construcció de l'emoció i l'empatia en els textos i les interaccions, i els seus efectes sobre la salut dels pacients. Es tracta d'un nou repte, alhora que un desenvolupament prometedor, que pot obrir vies d'investigació i pràctica professional en un tipus de comunicació altament sensible, on les paraules no només són portadores d'informació mèdica, sinó també desencadenants d'emocions que, si es gestionen correctament, poden contribuir al benestar - o, per contra, convertir-se en un obstacle - del lector o interlocutor meta.

\section{Referències bibliogràfiques}

ANDRIESEN, Simon. (2006) "Quality Control in Medical Translations." Innovations in Pharmaceutical Technology. Electronic version: <http://www.iptonline.com/ articles/public/IPT_25_p12NonPrint.pdf>

ASKeHAVE, Inger et al. (2010) "At styrke patienten i en New PublicmManagement verden: En udredning af betydningspotentialet i begrebet patient empowerment." In: Horsbøl, Anders \& Mariann B. Sørensen (eds.) 2010. Sundhedskommunikation på sygehuset. Aalborg: Aalborg Universitetsforlag, pp. 147-179.

ASKeHAVE, Inger \& Karen Korning Zethsen. (2000) The Patient Package Insert of the Future: (report for the Danish Ministry of Health). Århus: Handelshøjskolen i Århus, Det erhvervssproglige fakultet. 
AWAYSHEH, Abdullah; Jeffrey Wilcke; François Elvinger; Loren Rees; Weiguo Fan \& Kurt Zimmerman. (2017) "A review of medical terminology standards and structured reporting." Journal of Veterinary Diagnostic Investigation - Online First. Electronic version: <http://journals.sagepub.com/doi/ pdf/10.1177/1040638717738276>

CARDILLO, Elena. (2015) Mapping between international medical terminologies. Annex 4 to SHN Work Package 3. Electronic version: <http://www.semantichealthnet.eu/SemanticHealthNet/assets/File/SHN\%20288408\%20D3_3\%20 rev2\%20Annex\%204_Cardillo_SHN_D3_3_final.pdf>

Cimino, James J. (1998) "Desiderata for Controlled Medical Vocabularies in the Twenty-First Century." Methods of Information in Medicine 37:4-5, pp. 394-403. Council Directive 92/27/EEC.

DELÉGER, Louise; Tayeb Merabti; Thierry Lecrocq; Michel Joubert; Pierre Zweigenbaum \& Stéfan Darmoni. (2010) "A Twofold Strategy for Translating a Medical Terminology into French." AMIA Symposium Proceedings, pp. 152-156.

DŽUGANOVÁ, Božena. (2013) "English medical terminology - different ways of forming medical terms." JAHR - Annual of the Department of Social Sciences and Medical Humanities 4:7, pp. 55-69.

ENGEL, Uwe \& Britta Koester. (2014) "Response effects and the cognitive involvement in answering survey questions." In: Engel, Uwe; Ben Jann; Peter Lynn; Annette Scherpenzeel \& Patrick Sturgis (eds.) 2014. Improving Survey Methods Lessons from Recent Research. New York \& London: Routledge.

FAGe-Butler, Antoinette M. \& Matilde Nisbeth Jensen. (2016) "Medical terminology in online patient-patient communication: evidence of high health literacy?" Health Expectations 19:3, pp. 643-653.

FELBER, Helmut. (1984) Terminology Manual with emphasis on principles and methods. General Information Programme and UNISIST, Unesco International Information Centre for Terminology. Paris \& Vienna: Infoterm. Electronic version: <http://unesdoc.unesco.org/images/0006/000620/062033EB.pdf>

Fernández Piera, María \& Mónica Ardura Ortega. (2012) "Adaptación del consentimiento informado a la legislación española en los ensayos clínicos internacionales.”Panace@ 36:13, pp.291-293.

FLORES, Glenn et al. (2003) "Errors in medical interpretation and their potential clinical consequences in pediatric encounters." Pediatrics 111, pp. 6-14.

FUNG, Kin Wah et al. (2007) "Combining Lexical and Semantic Methods of InterTerminology Mapping Using the UMLS." Studies in Health Technology and Informatics 129, pp. 605-609. Electronic version: <https://www.ncbi.nlm.nih. gov/pmc/articles/PMC2430093/>

GotTI, Maurizio. (2011 [2008, 2005]) Investigating Specialized Discourse. Bern et al.: Peter Lang. 
GRUNWALD, David \& Norman Goldfarb. (2006) "Back Translation for Quality Control of Informed Consent Forms." Journal of Clinical Research Best Practices 2:2. Electronic version: <http://www.gts-translation.com/medicaltranslationpaper.pdf>

HolmströM, Inger \& Marta Röing. (2010) "The relation between patient-centeredness and patient empowerment: A discussion on concepts." Patient Education and Counseling 79, pp. 167-172.

International Council of Nurses (ICN). (2008) Translation Guidelines for International Classification of Nursing Practice (ICNP®). Geneva. Electronic version: <http://www.icn.ch/images/stories/documents/programs/icnp/icnp_ translation_guidelines.pdf>

International Council of Nurses (ICN). (2015) About ICNP®. Electronic version: <http://www.icn.ch/what-we-do/about-icnpr/>

International Medical Interpreters Association (IMIA). (2009) Guide on Medical Translation. Electronic version: <http://www.imiaweb.org/uploads/pages/438. pdf>

ISO 17100:2015 Translation Services-Requirements for Translation Services. International Organization for Standardization. Technical Committee ISO/ TC37.

MićIĆ, Sonja. (2013) "Languages of Medicine - present and future." JAHR - Annual of the Department of Social Sciences and Medical Humanities 4:7, pp. 217-233.

MitzKAT, Anika; Sarah Berger; Scott Reeves \& Cornelia Mahler. (2016) "More terminological clarity in the interprofessional field - a call for reflection on the use of terminologies, in both practice and research, on a national and international level." GMS Journal for Medical Education 33:2. Electronic version: <https:// www.ncbi.nlm.nih.gov/pmc/articles/PMC4895843/>

Montalt, Vicent. (2005) Manual de traducció cientificotècnica. Vic: Eumo.

Montalt, Vicent \& Maria González Davies. (2007) Medical translation step by step. Learning by drafting. New York: Routledge.

MONTALT, Vicent \& Mark Shuttleworth. (2012) Translation and knowledge mediation in healthcare settings. Linguistica Antverpiensia 11. Electronic version: <https://lans.ua.ac.be/index.php/LANS-TTS/issue/archive>

Montalt, Vicent. (2013) "Medical translation." In: Chapelle, Carol A. (ed.) 2013. The Encyclopaedia of Applied Linguistics. Oxford: Wiley-Blackwell.

MonTAlT, Vicent \& Isabel García-Izquierdo. (2016) "Exploring the link between the oral and the written in patient-doctor communication." In: OrdóñezLópez, Pilar \& Nuria Edo-Marzá (eds.) 2016. Medical Discourse in Professional, Academic and Popular Settings. Bristol, Buffalo \& Toronto: Multilingual Matters.

Montalt, Vicent (2017). "Patient-centred translation and emerging trends in medicine and healthcare." The EST Newsletter, European Society for Translation 
Studies. Electronic version: <http://www.est-translationstudies.org/committees/news_editors.html>

Nisbeth Jensen, Matilde \& Karen Korning Zethsen. (2012) "Translation of patient information leaflets: Trained translators and pharmacists-cum-translators - a comparison." Linguistica Antverpiensia. New Series. 11, pp. 31-49. Electronic version: <https://lans-tts.uantwerpen.be/index.php/LANS-TTS/ article/view/295/185>

Nisbeth Jensen, Matilde. (2013) Translators of Patient Information Leaflets: Translation experts or expert translators?: A mixed methods study of lay-friendliness. Aarhus: Aarhus University, Aarhus School of Business and Social Sciences. PhD thesis.

NutbEAm, Don. (2000) "Health literacy as a public health goal: a challenge for contemporary health education and communication strategies into the $21^{\text {st }}$ century contemporary health." Health Promotion International 15, pp. 259-267.

SAlager, Francoise. (1983) "The Lexis of Fundamental Medical English: Classificatory Framework and Rhetorical Function (A Statistical Approach)." Reading in a Foreign Language 1:1, pp. 54-64.

SAVAGE-Smith, Emilie. (2001) Islamic Medical Manuscripts at the National Library of Medicine. Rockville Pike: U.S. National Library of Medicine. Electronic version: <https://www.nlm.nih.gov/hmd/arabic/welcome.html>.

UHEROVÁ, Zdenka \& Anna Horňáková. (2013) "Medical terminology and its particularities." JAHR - Annual of the Department of Social Sciences and Medical Humanities 4:7, pp. 631-638.

WALLIS, Faith \& Robert Wisnovsky. (2016) "Introduction: Agents of Transmission, Translation and Transformation." In: Wallis, Faith \& Robert Wisnovsky (eds.) 2014. Medieval Textual Cultures: Agents of Transmission, Translation and Transformation (Judaism, Christianity, and Islam Tension, Transmission, Transformation), pp. 1-11. Berlin \& Boston: De Gruyer.

WAng, Amy Y.; James W. Barrett; Tim Bentley; David Markwell; Collin Price; Kent A. Spackman \& Michael Q. Stearns. (2001) "Mapping between SNOMED RT and Clinical terms version 3: A key component of the SNOMED CT development process." In: Bakken, Suzanne (ed.) 2001. AMIA Symposium Proceedings, pp. 741-745. Electronic version: <https://www.ncbi.nlm.nih.gov/pmc/articles/ PMC2243316/pdf/procamiasymp00002-0780.pdf>

World Health Organization (WHO). (1998) Health promotion glossary. Electronic version: <http://www.who.int/healthpromotion/about/HPR\%20Glossary\%20 1998.pdf>

World Health Organization (WHO). (2001) ICF: The International Classification of Functioning, Disability and Health. Electronic version: <http://apps.who.int/ classifications/icfbrowser/> 
World Health Organization (WHO). (2010) ICD-11 Revision project plan. <http:// www.who.int/classifications/icd/ICDRevisionProjectPlan_March2010.pdf> Zethsen, Karen. (2004) "Latin-based terms: True or false friends?" Target, 16, pp. 125-142.

\section{BIONOTAS}

VICENT MONTALT, màster en traducció i doctor en filologia anglesa, és professor titular del Departament de Traducció i Comunicació, Universitat Jaume I. Ha publicat nombrosos articles i llibres en els camps de la traductologia, la traducció científica i mèdica, la comunicació medicosanitària, la traducció teatral i Shakespeare. És director del Màster en traducció medicosanitària (EMT) i investigador del grup Gentt, tots dos de la Universitat Jaume I. És professor invitat del CenTraS, University College London.

KAREN KORNING ZETHSEN és catedràtica de traductologia a la Universitat d'Aarhus (Dinamarca). Entre els seus interessos d'investigació cal destacar la traductologia, la comunicació medicosanitària, la comunicació entre experts i no experts (traducció intralingüística) i la semàntica lèxica. Ha publicat nombrosos articles dins dels seus camps d'interès en revistes com ara Target, The Translator, TTR, Meta, Across Languages and Cultures, Jostrans, Document Design, Text \& Talk, Communication \& Medicine, Journal of Applied Linguistics and Professional Practice, Gender \& Language, Gender, Work \& Organization and the Journal of Pragmatics.

WiOletA KARWACKA és professora ajudant doctora al Departament de Traductologia de la Universitat de Gdańsk (Polònia). Els seus àmbits de recerca són els estudis traductològics, la traducció i la terminologia mèdiques, i l'antropomorfisme en la traducció. És autora de diversos articles i capítols de llibre sobre alguns aspectes de la traducció mèdica, com ara les qüestions de qualitat, les normes de traducció i la formació dels traductors. 
